\title{
Cumprimento da NBCAL quanto à comercialização de fórmulas infantis: Um comparativo entre Belém e São Paulo
}

\author{
Compliance with NBCAL on the sale of infant formula: A comparison between Belém and São Paulo \\ Cumplimiento de la NBCAL sobre la venta de fórmulas infantiles: una comparación entre Belém y \\ São Paulo
}

Recebido: 01/12/2021 | Revisado: 06/12/2021 | Aceito: 11/12/2021 | Publicado: 20/12/2021

\author{
Simone Dora Silva da Silva \\ ORCID: https://orcid.org/0000-0001-7922-7686 \\ Universidade Federal do Pará, Brasil \\ E-mail: sisi.six@gmail.com \\ Naíza Nayla Bandeira de Sá \\ ORCID: https://orcid.org/0000-0002-1267-1624 \\ Universidade Federal do Pará, Brasil \\ E-mail: naizasa@ufpa.br \\ Daniela Lopes Gomes \\ ORCID: https://orcid.org/0000-0002-0092-3396 \\ Universidade Federal do Pará, Brasil \\ E-mail: danielagomes@ufpa.br \\ Cristiano Siqueira Boccolini \\ ORCID: https://orcid.org/0000-0002-4804-5641 \\ Fundação Oswaldo Cruz, Brasil \\ E-mail: cristianoboccolini@gmail.com \\ Tereza Setsuko Toma \\ ORCID: https://orcid.org/0000-0001-9531-9951 \\ Instituto de Saúde, Brasil \\ E-mail: ttoma.ats@gmail.com
}

\begin{abstract}
Resumo
Objetivo: Avaliar as formas mais frequentes de infração à Norma Brasileira de Comercialização de Alimentos para Lactentes e Crianças de Primeira Infância, Bicos, Chupetas, Mamadeiras e Protetores de Mamilos - NBCAL, quanto à venda de fórmulas infantis cuja promoção comercial é proibida. Métodos: Realizou-se um estudo transversal em 2018 , em farmácias e supermercados nas cidades de Belém e São Paulo, que comercializavam os produtos abrangidos pela NBCAL, os entrevistadores foram capacitados quanto à NBCAL e utilizaram um formulário eletrônico estruturado para o registro das infrações encontradas nestes locais. A descrição dos dados foi feita pela frequência absoluta, relativa e IC-95\%. Resultados: Foram avaliados 200 estabelecimentos em Belém e 199 em São Paulo, dos quais, 11\% apresentaram infração na cidade de Belém e 9,5\% infringiram a Norma em São Paulo. As infrações mais frequentes foram: promoção de preço em Belém (52\%) e São Paulo (46,2\%), e exposição especial em Belém (10\%) e em São Paulo (35,9\%), foi possível verificar ainda a ocorrência simultânea das duas infrações em Belém (38\%) e em São Paulo $(17,9 \%)$. Conclusões: Apesar de ter transcorrido 32 anos desde a instituição da NBCAL, ainda se encontram infrações recorrentes à Legislação em produtos cuja promoção comercial é proibida, o presente estudo reforça a necessidade de maior fiscalização em estabelecimentos comerciais e de empresas que comercializam os produtos que são objetos da NBCAL.
\end{abstract}

Palavras-chave: Substitutos do leite humano; Fórmulas infantis; Comercialização de produtos; Promoção de alimentos; Aleitamento materno; Amamentação; Estudo multicentrico.

\footnotetext{
Abstract

Objective: Assess the most frequent forms of infringement of the Brazilian Norm for the Marketing of Food for Infants and Early Childhood Children, nipples, pacifiers, baby bottles and nipple protectors - NBCAL, regarding the sale of infant formulas whose commercial promotion is prohibited. Methods: A cross-sectional study was carried out in 2018 in pharmacies and supermarkets in the cities of Belém and São Paulo, which marketed the products covered by NBCAL, the interviewers were trained on the NBCAL and used a structured electronic form to record the infringements found. in these places. Data description was made by absolute and relative frequency and 95\%CI. Results: 200 establishments
} 
in Belém and 199 in São Paulo were evaluated, of which 11\% presented infractions in the city of Belém and 9.5\% breached the Standard in São Paulo. The most frequent infractions were: price promotion in Belém (52\%) and São Paulo (46.2\%), and special exhibition in Belém (10\%) and São Paulo (35.9\%), it was also possible to verify the simultaneous occurrence of the two offenses in Belém (38\%) and São Paulo (17.9\%). Conclusions: Although 32 years have passed since the institution of NBCAL, there are still recurrent infringements of the legislation in products whose commercial promotion is prohibited, this study reinforces the need for greater inspection in commercial establishments and companies that sell products that are NBCAL objects.

Keywords: Human milk substitutes; Infant formulas; Marketing of products; Food promotion; Breastfeeding; Breastfeeding; Multicentric study.

\section{Resumen}

Objetivo: Evaluar las formas más frecuentes de incumplimiento de la Norma Brasileña para la Comercialización de Alimentos para Lactantes y Primera Infancia, tetinas, chupetes, biberones y protectores de tetinas - NBCAL, en relación con la venta de fórmulas infantiles cuya promoción comercial está prohibida. Métodos: Se realizó un estudio transversal en 2018 en farmacias y supermercados de las ciudades de Belém y São Paulo, que comercializan los productos cubiertos por NBCAL, los entrevistadores fueron capacitados en la NBCAL y utilizaron un formulario electrónico estructurado para registrar las infracciones. encontrado en estos lugares. La descripción de los datos se realizó mediante frecuencia absoluta y relativa e IC del 95\%. Resultados: se evaluaron 200 establecimientos en Belém y 199 en São Paulo, de los cuales el 11\% presentó infracciones en la ciudad de Belém y el 9,5\% incumplió la Norma en São Paulo. Las infracciones más frecuentes fueron: promoción de precios en Belém (52\%) y São Paulo (46,2\%), y exhibición especial en Belém (10\%) y São Paulo (35,9\%), también se pudo verificar la ocurrencia simultánea de la dos delitos en Belém (38\%) y São Paulo (17,9\%). Conclusiones: Si bien han transcurrido 32 años desde la institución de NBCAL, aún existen infracciones recurrentes a la legislación en productos cuya promoción comercial está prohibida, este estudio refuerza la necesidad de una mayor fiscalización en establecimientos comerciales y empresas que comercializan productos que son objetos NBCAL.

Palabras clave: Sucedáneos de la leche materna; Fórmulas para bebés; Comercialización de productos; Promoción alimentaria; Amamantamiento; Estudio multicéntrico.

\section{Introdução}

A Organização das Nações Unidas (OMS) preconiza que a criança seja amamentada até os 2 anos ou mais, sendo que nos primeiros 6 meses de vida, o bebê deve receber apenas o leite materno, pois é o alimento mais completo contendo todos os nutrientes necessários à criança. Contudo, segundo a II Pesquisa de Prevalência em Aleitamento Materno nas capitais brasileiras e Distrito Federal, ocorrida no ano de 2008, apenas $41 \%$ dos bebês recebiam leite materno de forma exclusiva até o sexto mês, sendo a duração mediana de amamentação de 54,1 dias (Rocci \& Fernandes, 2014; Silva et al., 2014).

Segundo um estudo de coorte ocorrido no Sul do Brasil, que teve 3493 participantes, que foram monitorados por um período de 30 anos, teve como um de seus resultados a indicação de que a prática do aleitamento materno por mais de 12 meses traria uma grande repercussão no desenvolvimento cognitivo da criança (Oliveira et al., 2015).

Além disso, o aleitamento materno é apontado como uma das estratégias para se atingir a meta 4 dos Objetivos do Milênio (ODM) de redução da mortalidade infantil, principalmente por ser considerado o alimento padrão ouro para a nutrição dos lactentes (Amaral et al., 2015; Bridge et al., 2020).

A amamentação pode ser considerada ainda, como um dos quesitos de garantia aos Direitos Humanos, a partir da leitura de que o leite humano é a garantia de oferta do melhor, mais seguro e mais nutritivo alimento para o bebê e apresenta diversos benefícios a médio e longo prazo para a mãe (Grummer-Strawn et al., 2017).

Com o intuito de fortalecer o pilar de proteção da amamentação no ano de 1988, foi lançada a Norma Brasileira de Comercialização de Alimentos para Lactentes e Crianças de Primeira Infância, Bicos, Chupetas, Mamadeiras e Protetores de Mamilos - NBCAL, com o objetivo de monitorar e coibir a propaganda abusiva de substitutos do leite materno, esta Norma foi 
baseada no então Código Internacional de Comercialização de Substitutos do Leite Materno, proposto pela Organização Mundial da Saúde (OMS) no ano de 1981 (Cyrillo et al., 2009; Monteiro, 2006).

Segundo a Portaria $2.051 \mathrm{em} \mathrm{seu}$ artigo $4^{\circ}$, a Lei 11.265 também em seu artigo $4^{\circ}$ e a RDC nº $222 \mathrm{em}$ seu item 4.1, preveem que os produtos destinados à primeira infância (fórmulas infantis para lactentes, fórmulas infantis de seguimento para lactentes e fórmula de nutrientes para $\mathrm{RN}$ de alto risco) tem sua promoção comercial proibida, e que burlar esta norma geraria punições financeiras tanto para o estabelecimento comercial, quanto para os fabricantes destes produtos (Brasil, 2001; Brasil, 2002; Brasil, 2006; Araújo et al., 2006).

Entretanto, passados 32 anos de sua existência, os monitoramentos quanto ao cumprimento da Legislação, vêm demonstrando que ainda são realizadas infrações recorrentes à Norma, inclusive nos produtos que tem sua promoção comercial proibida (IBFAN, 2008; IBFAN, 2013; IBFAN, 2015; IDEC, 2013; IDEC, 2020).

Foi observado nos monitoramentos, daqueles que forneciam informações sobre a localidade pesquisada, que em Belém o monitoramento da legislação ocorreu apenas duas vezes, já quando observado o município de São Paulo, tal localidade esteve presente em todos os estudos já realizados, sendo o local de comparação mais indicado, uma vez que tem mapeamento contínuo fornece um parâmetro de comparação mais preciso no que diz respeito à aplicação da NBCAL (Toma et al., 2005; Toma et al., 2006; Salve et al., 2008; IBFAN, 2008, 2010, 2015; Salve et al.,; IDEC, 2020).

O presente estudo se propôs a comparar entre Belém e São Paulo quanto às formas mais frequentes de infração à NBCAL na venda de fórmulas infantis, cuja promoção comercial é proibida.

\section{Metodologia}

A presente pesquisa é parte integrante do Estudo Multicêntrico intitulado - "Estudo multicêntrico de avaliação do cumprimento da Norma Brasileira de Comercialização de Alimentos para Lactentes e Crianças de Primeira Infância, Bicos, Chupetas e Mamadeiras (Multi-NBCAL)", coordenado pela FIOCRUZ, aprovado pela Comissão Nacional de Ética em Pesquisa, sob o parecer $n^{\circ}$ 2.912.729. Trata-se de um estudo transversal, quantitativo, epidemiológico por meio de inquérito em estabelecimentos comerciais e hospitais com maternidade em 6 cidades do Brasil: de Rio de Janeiro (RJ), São Paulo (SP), Brasília (DF), João Pessoa (PB), Ouro Preto (MG), Florianópolis (SC) e Belém (PA), que objetivou avaliar o cumprimento da Norma Brasileira de Comercialização de Alimentos para Lactentes e Crianças de Primeira Infância, Bicos, Chupetas e Mamadeiras (NBCAL - Lei 11.265/06) nas diferentes regiões do Brasil.

Para este trabalho, foram utilizados apenas os dados referentes aos estabelecimentos comerciais dos municípios de Belém e de São Paulo. A coleta de dados nos dois centros foi realizada entre novembro e dezembro de 2018.

Estabeleceu-se um número mínimo de 200 estabelecimentos comerciais, para cada centro, em amostra propositiva; este número amostral foi calculado tendo por base uma estimativa de prevalência de infrações à NBCAL de 50\%, com margem de erro de $3 \%$ e intervalo de confiança de $95 \%$.

Após a definição do tamanho amostral, procedeu-se à identificação dos estabelecimentos comerciais do tipo farmácias e supermercados. Para essa identificação, foi realizado um levantamento em 4 (quatro) etapas: 1) levantamento dos estabelecimentos comerciais entre farmácias e supermercados, por meio de pesquisa eletrônica dos termos: "farmácia", "drogaria", "supermercado" e "meio a meio"; 2) foi requerida à Vigilância Sanitária local a lista dos estabelecimentos que comercializavam os produtos abrangidos pela Norma; 3) Foi realizado o cruzamento das listas para checagem de telefones e endereços dos estabelecimentos comerciais das duas capitais; 4) Fez-se a busca ativa in loco nas ruas das cidades de Belém e de São Paulo.

Em Belém, foi realizada a coleta de dados em todas farmácias e/ou supermercados existentes em seu território, uma vez que foram constatados 200 estabelecimentos nesta localidade. Na cidade de São Paulo, se elegeu intencionalmente, uma região 
de bairros contíguos, que abarcasse populações com diferentes estratos socioeconômicos e que compreendessem ao menos 200 estabelecimentos comerciais elegíveis. Ao final, foi elaborada uma lista única de estabelecimentos entre farmácias e supermercados que comercializavam os produtos objeto deste estudo, contendo o nome do estabelecimento, endereço e bairro.

Foram incluídos neste estudo, as farmácias/drogarias e supermercados/meio-a-meio que comercializavam ao menos um dos produtos abrangidos pela NBCAL. Foram excluídos deste estudo, os estabelecimentos comerciais que não eram caracterizados como farmácias/drogarias e supermercados/meio-a-meio, mesmo que comercializassem os produtos abrangidos pela NBCAL.

Para a realização da coleta, foram recrutados em cada centro colaborador entrevistadores, nos cursos de graduação e de pós-graduação da área da saúde, estes entrevistadores foram treinados por meio do "Curso de Capacitação na Norma Brasileira de Comercialização de Alimentos para Lactentes e Crianças de Primeira Infância, Bicos, Chupetas e Mamadeiras - NBCAL", que teve duração de dois dias e carga horária de 20 horas, com aulas teóricas acerca da NBCAL e treinamento prático em estabelecimentos comerciais para a identificação das infrações por meio do software Magpi+®. Após a formação, os pesquisadores receberam uma lista com os endereços dos estabelecimentos a serem pesquisados por cada um.

Em São Paulo (SP) foram pesquisados 216 estabelecimentos, destes foram excluídos um total de 17, sendo 14 por não ter sido identificado o tipo de estabelecimento e 3 por não se enquadrarem no tipo de estabelecimentos pesquisados (farmácias/drogarias ou supermercados/hipermercados), ficando a amostra final em 199 estabelecimentos. Em Belém (PA) foram pesquisados 200 estabelecimentos, sem nenhuma perda amostral.

A descrição dos dados foi feita pela frequência absoluta, relativa e considerando o Intervalo de Confiança de 95\%, sendo apresentados em formato de tabelas e um gráfico. Para verificar a diferença entre as duas cidades quanto à caracterização dos estabelecimentos pesquisados e perfil das infrações cometidas, aplicaram-se testes não paramétricos, teste qui-quadrado de independência, quando não foram preenchidos os requisitos do teste do qui-quadrado, aplicou-se o teste G. As análises foram feitas no programa BioEstat 5.3 e considerou-se o nível de significância de 5\%.

\section{Resultados}

A Tabela 1 mostra a caracterização dos 199 estabelecimentos pesquisados em São Paulo (SP) e 200 estabelecimentos de Belém (PA). Quanto à caracterização dos estabelecimentos pesquisados em Belém e São Paulo, verificaram-se diferenças significativas no tamanho do estabelecimento $(\mathrm{p}<0,001)$, tipo de estabelecimento $(\mathrm{p}=0,001)$ e se fazia parte de uma rede $(\mathrm{p}=0,017)$. Dessa forma, em Belém, o maior quantitativo foi de estabelecimentos de médio porte (41,0\%) e em São Paulo a maior concentração era de pequeno porte $(54,3 \%)$. As farmácias e drogarias foram os principais estabelecimentos pesquisados em Belém, representando 71,5\% do total, já em São Paulo houve maior uniformidade na distribuição do tipo de estabelecimento, mas um pouco mais da metade eram farmácias ou drogarias, totalizando $54,8 \%$. 
Tabela 1. Caracterização dos estabelecimentos pesquisados em Belém e São Paulo.

\begin{tabular}{|c|c|c|c|c|c|}
\hline \multirow{2}{*}{ Variáveis } & \multicolumn{2}{|c|}{ Belém } & \multicolumn{2}{|r|}{ São Paulo } & \multirow{2}{*}{ p-valor* } \\
\hline & $\mathbf{n}$ & $\%(\mathrm{IC} 95 \%)$ & $\mathbf{n}$ & $\%($ IC95\%) & \\
\hline Tamanho do estabelecimento & & & & & $<0,001 * *$ \\
\hline Pequeno & 44 & $22,0(16,8-28,2)$ & 108 & $54,3(47,3-61,0)$ & \\
\hline Médio & 82 & $41,0(34,4-47,9)$ & 84 & $42,2(35,6-49,2)$ & \\
\hline Grande & 51 & $25,5(20,0-32,0)$ & 6 & $3,0(1,4-6,4)$ & \\
\hline Hiper & 23 & $11,5(7,8-16,7)$ & 1 & $0,5(0,1-2,8)$ & \\
\hline Tipo de estabelecimento & & & & & 0,001 \\
\hline Farmácias e drogarias & 143 & $71,5(64,9-77,3)$ & 109 & $54,8(47,8-61,5)$ & \\
\hline Supermercados e atacados & 57 & $28,5(22,7-35,1)$ & 90 & $45,2(38,5-52,2)$ & \\
\hline Faz parte de uma Rede & & & & & 0,017 \\
\hline Não & 26 & $13,0(9,0-18,4)$ & 44 & $22,1(16,9-28,4)$ & \\
\hline Sim & 174 & $87,0(81,6-91,0)$ & 155 & $77,9(71,6-83,1)$ & \\
\hline Apresenta infração à NBCAL & & & & & 0,633 \\
\hline Não & 178 & $89,0(83,9-92,6)$ & 180 & $90,5(85,6-93,8)$ & \\
\hline Sim & 22 & $11,0(7,4-16,1)$ & 19 & $9,5(6,2-14,4)$ & \\
\hline $\begin{array}{l}\text { Apresenta infração em fórmulas } \\
\text { infantis para lactentes }\end{array}$ & & & & & 0,409 \\
\hline Não & 178 & $89,0(83,9-92,6)$ & 182 & $91,5(86,7-94,6)$ & \\
\hline Sim & 22 & $11,0(7,4-16,1)$ & 17 & $8,5(5,4-13,3)$ & \\
\hline $\begin{array}{l}\text { Apresenta infração em fórmulas } \\
\text { infantis de seguimento para } \\
\text { lactentes }\end{array}$ & & & & & 0,424 \\
\hline Não & 194 & $97,0(93,6-98,6)$ & 190 & $95,5(91,6-97,6)$ & \\
\hline Sim & 6 & $3,0(1,4-6,4)$ & 9 & $4,5(2,4-8,4)$ & \\
\hline Promoção de preço & & & & & 0,494 \\
\hline Não & 180 & $90,0(85,1-93,4)$ & 183 & $92,0(87,3-95,0)$ & \\
\hline Sim & 20 & $10,0(6,6-14,9)$ & 16 & $8,0(5,0-12,7)$ & \\
\hline Exposição especial & & & & & 0,128 \\
\hline Não & 189 & $94,5(90,4-96,9)$ & 194 & $97,5(94,3-98,9)$ & \\
\hline Sim & 11 & $5,5(3,1-9,6)$ & 5 & $2,5(1,1-5,7)$ & \\
\hline Total de estabelecimentos & 200 & 100,0 & 199 & 100,0 & \\
\hline
\end{tabular}

*Teste do qui-quadrado. **Teste G. Fonte: Autores (2019).

Em Belém, houve maior frequência de estabelecimentos que faziam parte de uma rede 87,0\%, em São Paulo a concentração foi de 77,9\%. Em Belém, a prevalência de infração à NBCAL foi de 11,0\%, semelhante ao observado em São Paulo, com 9,5\%. Também nas duas cidades foi maior a prevalência de infrações em fórmulas infantis para lactentes, do que nas fórmulas de seguimento e não foram observadas infração em fórmulas de nutrientes para recém-nascidos de alto risco. Ainda, nas duas capitais o tipo de infração foi de promoção de preço e de exposição especial dos produtos, com prevalência semelhante (Tabela 1).

A Tabela 2 apresenta a caracterização das infrações à NBCAL segundo o tipo de fórmula infantil, o tamanho do estabelecimento, tipo de estabelecimento comercial, nome da empresa e tipo de infrações cometidas nos 199 estabelecimentos de São Paulo (SP) e 200 estabelecimentos de Belém (PA). Foram observadas 50 infrações em 22 estabelecimentos de Belém e 39 infrações em 19 estabelecimentos de São Paulo. Em média, os estabelecimentos de Belém cometeram 2,2 infrações e em São Paulo 2,1. 
Tabela 2. Comparação entre Belém e São Paulo quanto às infrações a NBCAL segundo o tipo de fórmula, o tamanho do estabelecimento, tipo de estabelecimento comercial, nome da empresa, nome do produto e tipo de infrações cometidas.

\begin{tabular}{|c|c|c|c|c|c|}
\hline \multirow{2}{*}{ Variáveis } & \multicolumn{2}{|c|}{ Belém } & \multicolumn{2}{|c|}{ São Paulo } & \multirow{2}{*}{ p-valor* } \\
\hline & n & $\%(\mathrm{IC} 95 \%)$ & $\mathbf{n}$ & $\%($ IC95\%) & \\
\hline Tipo de fórmulas infantis & & & & & 0,883 \\
\hline Fórmulas infantis para lactentes & 30 & $60,0(46,2-72,4)$ & 24 & $61,5(45,9-75,1)$ & \\
\hline $\begin{array}{l}\text { Fórmulas infantis de seguimento para } \\
\text { lactentes }\end{array}$ & 20 & $40,0(27,6-53,8)$ & 15 & $38,5(24,9-54,1)$ & \\
\hline Tamanho do estabelecimento & & & & & $<0,001 * *$ \\
\hline Pequeno & 11 & $22,0(12,8-35,2)$ & 10 & $25,6(14,6-41,1)$ & \\
\hline Médio & 19 & $38,0(25,9-51,8)$ & 29 & $74,4(58,9-85,4)$ & \\
\hline Grande & 9 & $18,0(9,8-30,8)$ & 0 & $0,0(0,0-9,0)$ & \\
\hline Hiper & 11 & $22,0(12,8-35,2)$ & 0 & $0,0(0,0-9,0)$ & \\
\hline Tipo de estabelecimento & & & & & 0,696 \\
\hline Farmácias e drogarias & 38 & $76,0(62,6-85,7)$ & 31 & $79,5(64,5-89,2)$ & \\
\hline Supermercados e atacados & 12 & $24,0(14,3-37,4)$ & 8 & $20,5(10,8-35,5)$ & \\
\hline Empresa fabricante & & & & & $0,347 * *$ \\
\hline Biolab & 1 & $2,0(0,4-10,5)$ & 3 & $7,7(2,7-20,3)$ & \\
\hline Danone & 19 & $22,0(12,8-35,2)$ & 17 & $43,6(29,3-59,0)$ & \\
\hline Mead Johnson & 1 & $2,0(0,4-10,5)$ & 2 & $5,1(1,4-16,9)$ & \\
\hline Nestlé & 29 & $58,0(44,2-70,6)$ & 17 & $43,6(29,3-59,0)$ & \\
\hline \multicolumn{6}{|l|}{ Presença de infração no produto } \\
\hline Aptamil & 15 & $30,0(19,1-43,8)$ & 15 & $38,5(24,9-54,1)$ & 0,402 \\
\hline Enfamil & 1 & $2,0(0,4-10,5)$ & 2 & $5,1(1,4-16,9)$ & $0,417 * *$ \\
\hline Milupa & 2 & $4,0(1,1-13,5)$ & 1 & $2,6(0,5-13,2)$ & $0,706^{* *}$ \\
\hline NAN & 23 & $46,0(33,0-59,6)$ & 7 & $17,9(9,0-32,7)$ & 0,006 \\
\hline Nestogeno & 6 & $12,0(5,6-23,8)$ & 10 & $25,6(14,6-41,1)$ & 0,096 \\
\hline Neocate & 1 & $2,0(0,4-10,5)$ & 0 & $0,0(0,0-9,0)$ & $0,281 * *$ \\
\hline Novamil & 1 & $2,0(0,4-10,5)$ & 3 & $7,7(2,7-20,3)$ & $0,195 * *$ \\
\hline Pregomin & 1 & $2,0(0,4-10,5)$ & 1 & $2,6(0,5-13,2)$ & $0,859 * *$ \\
\hline Tipos de infrações observadas & & & & & $0,006^{*}$ \\
\hline Promoção de preço & 26 & $52,0(38,5-65,2)$ & 18 & $46,2(31,6-61,4)$ & \\
\hline Exposição especial & 5 & $10,0(4,3-21,4)$ & 14 & $35,9(22,7-51,6)$ & \\
\hline $\begin{array}{l}\text { Promoção de preço e exposição } \\
\text { especial }\end{array}$ & 19 & $38,0(25,9-51,8)$ & 7 & $17,9(9,0-32,7)$ & \\
\hline Total de infrações & 50 & 100,0 & 39 & 100,0 & \\
\hline
\end{tabular}

*Teste do qui-quadrado. **Teste G. Fonte: Autores (2019).

Observaram-se diferenças significativas na distribuição da quantidade de infrações em Belém e São Paulo quanto ao tamanho do estabelecimento $(\mathrm{p}<0,001)$ e tipo de infração $(\mathrm{p}=0,006)$. Em Belém foram distribuídas as infrações nos estabelecimentos de tamanho pequeno (22,0\%), médio (38,0\%), grande (18,0\%) e hiper (22,0\%), enquanto que em São Paulo as infrações foram concentradas apenas em estabelecimentos de pequeno $(25,6 \%)$ e de médio porte $(74,4 \%)$. Houve semelhanças entre as duas capitais quanto a maior frequência de infração do tipo promoção de preço e diferenças quanto à frequência de infração do tipo exposição especial, sendo esta significativamente maior em Belém do que em São Paulo (Tabela 2).

O Gráfico 1 apresenta a distribuição da frequência de infrações segundo o fabricante. Apesar de em Belém ter sido maior o número de infrações na empresa Nestlé e Danone do que em São Paulo, essas diferenças não foram significativas. 
Gráfico 1 - Comparação entre as infrações à NBCAL em fórmulas infantis em Belém e São Paulo, segundo o fabricante. Belém-PA, 2019.

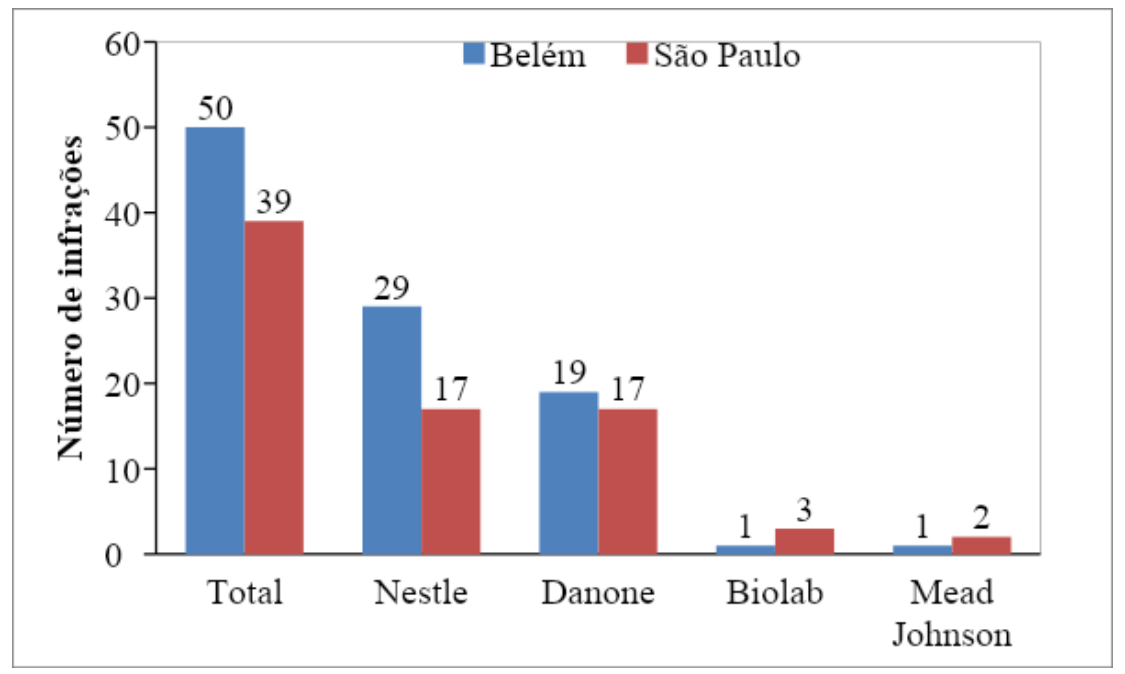

Fonte: Autores (2019).

A Tabela 3 mostra a comparação das infrações cometidas nas duas capitais segundo o tamanho do estabelecimento. Em Belém, as farmácias e drogarias que apresentaram infrações à NBCAL eram de pequeno e médio porte, enquanto que os supermercados eram de tamanho grande ou hiper ( $p<0,001)$. Já em São Paulo não foi observada essa associação.

Tabela 3. Comparação entre Belém e São Paulo quanto às infrações a NBCAL segundo o tamanho do estabelecimento comercial.

\begin{tabular}{|c|c|c|c|c|c|c|c|c|c|c|}
\hline \multirow[b]{2}{*}{ Infrações } & \multicolumn{5}{|c|}{ Belém } & \multirow[b]{2}{*}{ p-valor* } & \multicolumn{3}{|c|}{ São Paulo } & \multirow[b]{2}{*}{$\begin{array}{c}\text { p- } \\
\text { valor* }\end{array}$} \\
\hline & $\frac{\text { Pequeno }}{\mathrm{n}(\%)}$ & $\frac{\text { Médio }}{\text { n (\%) }}$ & $\frac{\text { Grande }}{\text { n }(\%)}$ & $\begin{array}{l}\text { Hiper } \\
\text { n }(\%)\end{array}$ & $\frac{\text { Total }}{\text { n }(\%)}$ & & $\frac{\text { Pequeno }}{\text { n }(\%)}$ & $\frac{\text { Médio }}{\text { n }(\%)}$ & $\frac{\text { Total }}{\text { n }(\%)}$ & \\
\hline $\begin{array}{l}\text { Tipo de fórmulas } \\
\text { infantis }\end{array}$ & & & & & & 0,995 & & & & 0,907 \\
\hline $\begin{array}{l}\text { Fórmulas infantis } \\
\text { para lactentes }\end{array}$ & $8(72,7)$ & $12(63,2)$ & $5(55,6)$ & $7(63,6)$ & $32(64,0)$ & & $6(60,0)$ & $18(62,1)$ & $24(61,5)$ & \\
\hline $\begin{array}{l}\text { Fórmulas infantis de } \\
\text { seguimento para } \\
\text { lactentes }\end{array}$ & $3(27,3)$ & $7(36,8)$ & $4(44,4)$ & $4(36,4)$ & $18(36,0)$ & & $4(40,0)$ & $11(37,9)$ & $15(38,5)$ & \\
\hline $\begin{array}{l}\text { Tipo do } \\
\text { estabelecimento }\end{array}$ & & & & & & $<0,001$ & & & & 0,403 \\
\hline Farmácia e drogarias & $\begin{array}{c}11 \\
(100,0)\end{array}$ & $19(100,0)$ & $8(88,9)$ & $0(0,0)$ & $28(56,0)$ & & $7(70,0)$ & $24(82,8)$ & $31(79,5)$ & \\
\hline $\begin{array}{l}\text { Supermercados e } \\
\text { atacados }\end{array}$ & $0(0,0)$ & $\begin{array}{c}0 \\
(0,0)\end{array}$ & $1(11,1)$ & $11(100,0)$ & $12(24,0)$ & & $3(30,0)$ & $5(17,2)$ & $8(20,5)$ & \\
\hline Empresa fabricante & & & & & & 0,521 & & & & 0,384 \\
\hline Biolab & $0(0,0)$ & $\begin{array}{c}0 \\
(0,0)\end{array}$ & $1(11,1)$ & $0(0,0)$ & $1(2,0)$ & & $\begin{array}{c}0 \\
(0,0)\end{array}$ & $3(10,3)$ & $3(7,7)$ & \\
\hline Danone & $5(45,5)$ & $6(31,6)$ & $3(33,3)$ & $5(45,5)$ & $19(38,0)$ & & $6(60,0)$ & $11(37,9)$ & $17(43,6)$ & \\
\hline Mead Johnson & $0(0,0)$ & $\begin{array}{c}0 \\
(0,0)\end{array}$ & $1(11,1)$ & $0(0,0)$ & $1(2,0)$ & & $1(10,0)$ & $\begin{array}{c}1 \\
(3,5)\end{array}$ & $2(5,1)$ & \\
\hline Nestlé & $6(54,5)$ & $13(68,4)$ & $4(44,4)$ & $6(54,5)$ & $29(58,0)$ & & $3(30,0)$ & $14(48,3)$ & $17(43,6)$ & \\
\hline Tipo de infrações & & & & & & 0,026 & & & & 0,900 \\
\hline Promoção de preço & $4(36,4)$ & $9(47,4)$ & $2(22,2)$ & $11(100,0)$ & $26(52,0)$ & & $5(50,0)$ & $13(44,8)$ & $18(46,2)$ & \\
\hline Exposição especial & $4(36,4)$ & $\begin{array}{c}0 \\
(0,0)\end{array}$ & $1(11,1)$ & $0(0,0)$ & $5(10,0)$ & & $3(30,0)$ & $11(37,9)$ & $14(35,9)$ & \\
\hline $\begin{array}{l}\text { Promoção de preço e } \\
\text { exposição especial }\end{array}$ & $3(27,3)$ & $10(52,6)$ & $6(66,7)$ & $0(0,0)$ & $19(38,0)$ & & $2(20,0)$ & $5(17,2)$ & $7(17,9)$ & \\
\hline Total de infrações & $11(22,0)$ & $19(38,0)$ & $9(18,0)$ & $11(22,0)$ & $50(100,0)$ & & $10(25,6)$ & $29(74,4)$ & $39(100,0)$ & \\
\hline
\end{tabular}

*Teste G. Fonte: Autores (2019).

Na capital paraense houve associação entre o tamanho do estabelecimento e o tipo de infração. A infração do tipo promoção de preço foi maior entre os hipermercados, a infração do tipo exposição especial foi maior entre os pequenos 
estabelecimentos e o acometimento concomitante de infração do tipo promoção de preço com exposição especial foi maior entre os médios e grandes estabelecimentos ( $\mathrm{p}=0,026)$. Diferente de Belém, em São Paulo não houve associação entre o tamanho do estabelecimento e o tipo de infração cometida, sendo em pequenos e médios estabelecimentos maior a presença de infração do tipo promoção de preço (Tabela 3).

A Tabela 4 apresenta a comparação das infrações cometidas nas duas capitais segundo o tipo de estabelecimento. Em São Paulo, encontraram-se diferenças significativas nas infrações segundo o tipo de estabelecimento quando avaliada as empresas fabricantes dos produtos $(\mathrm{p}=0,045)$, sendo maior a frequência de infrações na marca Danone em Farmácias/drogarias e na marca Nestlé em supermercados/atacados, mas não foi observada essa relação em Belém.

Tabela 4. Comparação entre Belém e São Paulo quanto às infrações cometidas segundo o tipo de estabelecimento comercial.

\begin{tabular}{|c|c|c|c|c|c|c|c|c|}
\hline \multirow{3}{*}{ Infrações } & \multicolumn{3}{|c|}{ Belém } & \multirow{3}{*}{$\begin{array}{c}\text { p- } \\
\text { valor* }\end{array}$} & \multicolumn{3}{|c|}{ São Paulo } & \multirow{3}{*}{$\begin{array}{c}\text { p- } \\
\text { valor* }\end{array}$} \\
\hline & $\begin{array}{l}\text { Farmácias } \\
\text { e drogarias }\end{array}$ & $\begin{array}{c}\text { Supermercados } \\
\text { e atacados }\end{array}$ & Total & & $\begin{array}{l}\text { Farmácias } \\
\text { e drogarias }\end{array}$ & $\begin{array}{c}\text { Supermercados } \\
\text { e atacados }\end{array}$ & Total & \\
\hline & n (\%) & n (\%) & n (\%) & & n (\%) & $\mathrm{n}(\%)$ & n (\%) & \\
\hline $\begin{array}{l}\text { Tipo de fórmulas } \\
\text { infantis }\end{array}$ & & & & 0,496 & & & & 0,758 \\
\hline $\begin{array}{l}\text { Fórmulas infantis } \\
\text { para lactentes }\end{array}$ & $32(84,2)$ & $11(91,7)$ & $\begin{array}{c}43 \\
(86,0)\end{array}$ & & $20(64,5)$ & $4(50,0)$ & $24(61,5)$ & \\
\hline $\begin{array}{l}\text { Fórmulas infantis } \\
\text { de seguimento } \\
\text { para lactentes }\end{array}$ & $6(15,8)$ & $1(8,3)$ & $7(14,0)$ & & $11(35,5)$ & $4(50,0)$ & $15(38,5)$ & \\
\hline $\begin{array}{l}\text { Tamanho do } \\
\text { estabelecimento }\end{array}$ & & & & $<0,001$ & & & & 0,873 \\
\hline Pequeno & $11(28,9)$ & $0(0,0)$ & $\begin{array}{c}11 \\
(22,0) \\
\end{array}$ & & $7(22,6)$ & $3(37,5)$ & $10(25,6)$ & \\
\hline Médio & $19(50,0)$ & $0(0,0)$ & $1938,0)$ & & $24(77,4)$ & $5(62,5)$ & $29(74,4)$ & \\
\hline Grande & $8(21,1)$ & $1(8,3)$ & $9(18,0)$ & & $0(0,0)$ & $0(0,0)$ & $0(0,0)$ & \\
\hline Hiper & $0(0,0)$ & $11(91,7)$ & $\begin{array}{c}11 \\
(22,0) \\
\end{array}$ & & $0(0,0)$ & $0(0,0)$ & $0(0,0)$ & \\
\hline $\begin{array}{l}\text { Empresa } \\
\text { fabricante }\end{array}$ & & & & 0,606 & & & & 0,045 \\
\hline Biolab & $1(2,6)$ & $0(0,0)$ & $1(2,0)$ & & $3(9,7)$ & $0(0,0)$ & $3(7,7)$ & \\
\hline Danone & $13(34,2)$ & $6(50,0)$ & $\begin{array}{c}19 \\
(38,0)\end{array}$ & & $15(48,4)$ & $2(25,0)$ & $17(43,6)$ & \\
\hline Mead johnson & $1(2,6)$ & $0(0,0)$ & $1(2,0)$ & & $2(6,4)$ & $0(0,0)$ & $2(5,1)$ & \\
\hline Nestlé & $23(60,5)$ & $6(50,0)$ & $\begin{array}{c}29 \\
(58,0)\end{array}$ & & $11(35,5)$ & $6(75,0)$ & $17(43,6)$ & \\
\hline Tipo de infrações & & & & $<0,001$ & & & & 0,016 \\
\hline $\begin{array}{l}\text { Promoção de } \\
\text { preço }\end{array}$ & $14(36,8)$ & $12(100,0)$ & $\begin{array}{c}26 \\
(52,0) \\
\end{array}$ & & $12(38,7)$ & $6(75,0)$ & $18(46,2)$ & \\
\hline $\begin{array}{l}\text { Exposição } \\
\text { especial }\end{array}$ & $5(13,2)$ & $0(0,0)$ & $5(16,0)$ & & $14(45,2)$ & $0(0,0)$ & $14(35,9)$ & \\
\hline $\begin{array}{l}\text { Promoção de } \\
\text { preço e exposição } \\
\text { especial }\end{array}$ & $19(50,0)$ & $0(0,0)$ & $\begin{array}{c}19 \\
(38,0)\end{array}$ & & $5(16,1)$ & $2(25,0)$ & $7(17,9)$ & \\
\hline $\begin{array}{l}\text { Total de } \\
\text { infrações }\end{array}$ & $38(76,0)$ & $12(24,0)$ & $\begin{array}{c}50 \\
(100,0) \\
\end{array}$ & & $31(62,0)$ & $8(16,0)$ & $39(100,0)$ & \\
\hline
\end{tabular}

* Teste G. Fonte: Autores (2019).

Em Belém e São Paulo houve relação entre o tipo de estabelecimento com o tipo infração cometida, sendo maior entre os supermercados e atacados a presença de infração do tipo promoção de preço e a exposição especial foi maior entre as farmácias e drogarias $(\mathrm{p}<0,001)$. 


\section{Discussão}

A partir das análises dos resultados, foi possível observar que a NBCAL vem sendo descumprida no que tange a promoção comercial proibida em produtos destinados à primeira infância, mesmo havendo monitoramentos sistemáticos e aplicação das penalidades previstas em Lei (Toma et al., 2005; Toma et al., 2006; Salve et al., 2008; IBFAN, 2008; IBFAN, 2010; IBFAN, 2015; Salve et al., 2011; IDEC, 2020).

Em seu estudo Piwoz e Huffman (2015) retratou que globalmente as vendas de fórmulas de leite cresceram de US \$ 2 bilhões em 1987, para cerca de US \$ 40 bilhões em 2013, representando dois terços de todas as vendas de alimentos para bebês internacionalmente.

Piwoz e Huffman (2015) apontaram que do total de fórmulas de leite comercializados, aproximadamente $39 \%$ eram fórmulas infantis indicadas para bebês abaixo de 6 meses, $25 \%$ eram fórmulas de acompanhamento indicadas para crianças de 6 a 11 meses e leites de crescimento para crianças acima de 12 meses, o restante totalizando $11 \%$ relacionavam-se a leites especiais, a exemplo dos indicados para crianças com baixo peso ao nascer.

No ano de 2014, as vendas de substitutos do leite humano tiveram um lucro estimado de US \$44,8 bilhões, tendo uma projeção para o ano de 2019 de um aumento do faturamento para US \$71 bilhões (Grummer-Strawn et al., 2017; HernándezCordero et al., 2019).

Grummer-Strawn et al. (2017) destacaram ainda que a nível mundial há uma ampla promoção dos substitutos do leite materno, em países como Camboja, Senegal, Nepal, além de várias violações no campo da saúde e nutrição, com o intuito de criar uma impressão de equiparação da qualidade das fórmulas infantis ao leite materno.

No presente estudo, foram observados em Belém e São Paulo uma prevalência de infração à NBCAL de produtos cuja promoção comercial é proibida de $11,0 \%$ e 9,5\% respectivamente, Silva et al. (2020) em seu estudo tiveram achados semelhantes quanto a comercialização das fórmulas infantis, com uma prevalência de infração de 16,0\%.

No estudo de Paula et al. (2010) os resultados encontrados ratificaram os achados deste estudo, com um total de 14 lojas em não conformidade para promoção comercial de fórmulas infantis para lactentes, bicos, chupetas e mamadeiras, o artigo o qual estava sendo infringido era o item 4.1 da Resolução RDC n 222, e o item 6.2 da Resolução RDC n 221.

Nas duas localidades pesquisadas, as formas mais frequentes de infração foram a promoção de preço em Belém, com um total de 52\% e em São Paulo foi maior o registro de infração do tipo exposição especial 35,9\% do que na capital paraense, mas é importante ressaltar que houve uma frequência significativa de infrações concomitantes de promoção de preço e exposição especial, com um total de $38 \%$ na cidade paraense. No estudo, Silva et al. (2020) os achados se assemelham, com as infrações mais recorrentes análogas de desconto nos preços e exposição especial.

Da mesma forma, Hadihardjono et al. (2019) observaram em seu estudo ocorrido cidade de Bandung na Indonésia, que uma das formas mais frequentes de infração a legislação foi a do tipo promoção de exibição, que equivale a exposição especial aqui no Brasil, ocorrendo em 53,3\% das fórmulas infantis destinadas a bebês de 0 a 5 meses de idade, e 53,8\% ocorreram em fórmulas de acompanhamento destinadas a bebês de 6 a 11 meses, cabe ressaltar que a Indonésia acompanha as diretrizes do Código Internacional de Marketing Substitutos do Leite Materno que assim como no Brasil, proíbe a promoção comercial de produtos destinados a crianças de 0 a 12 meses.

No quesito promoção comercial, Paula et al. (2010) observaram que ainda ocorriam de forma frequente, tanto a venda casada de produtos, exposição especial, desconto na compra de mais de um volume, dentre outras infrações. Além da oferta de vantagens aos donos dos estabelecimentos.

Assim como no presente estudo, Zhao et al. (2019) similarmente observaram a ocorrência de promoções de preços especiais como descontos, vendas e ofertas de tempo limitado em quase metade de sua amostra, cerca de $49 \%$ de todos os 
produtos avaliados. Observaram ainda 11 ocorrências de promoções em fórmulas lácteas infantis, destinadas a crianças menores de 36 meses, cuja promoção comercial é proibida em seu país.

Hernández-Cordero et al. (2019) verificaram que dos 51 estabelecimentos visitados, 50 deles apresentavam alguma publicidade em substitutos do leite materno, como principais achados, verificaram um total de $60 \%$ de infrações do tipo promoções de preços, $20 \%$ do tipo embalagens promocionais e $16 \%$ do tipo amostras grátis.

Já quanto ao tipo de estabelecimento em que se concentraram as infrações, tanto em Belém quanto em São Paulo, as farmácias/drogarias tiveram os maiores registros de infrações com 38 e 31 violações respectivamente. Achados equivalentes foram observados no estudo de Silva et al. (2020) no qual a concentração das infrações ocorreu também em farmácias, com um total de 44 descumprimentos nos estabelecimentos pesquisados. Em seu estudo Pries et al. (2016), constataram que as lojas ou farmácias apresentaram uma concentração de $24,1 \%$ das promoções de substitutos do leite materno.

Quanto ao tamanho do estabelecimento, em Belém, observou-se que houve uma distribuição das infrações em pequenos, médios, grandes e hiper estabelecimentos, sendo mais recorrente em estabelecimentos de médio porte, totalizando 38\% do total de infrações encontradas. Em contrapartida, em São Paulo, as infrações se concentraram apenas em estabelecimentos de pequeno e médio porte. Nos dois locais, o maior número de infrações ocorreu em estabelecimentos de médio porte, com 74,4\% das violações encontradas.

As Empresas que mais tiveram achados em desacordo com a Legislação foram a Nestlé ${ }^{\circledR}$ e a Danone ${ }^{\circledR}$ nas duas localidades, a frequência em Belém foi de 58\% e 22\% respectivamente, já em São Paulo a frequência foi igual totalizando 43,6\% de infrações tanto dos produtos da Empresa Nestlé ${ }^{\circledR}$, quanto de produtos da Empresa Danone ${ }^{\circledR}$. Em seu estudo, Silva et al. (2020) observaram do mesmo modo que as Empresas Nestlé ${ }^{\circledR}$ e a Danone ${ }^{\circledR}$ foram as que apresentaram as maiores frequências de infrações em fórmulas infantis.

No estudo ocorrido na cidade de Bandung na Indonésia, foi verificado que as Empresas Nutricia ${ }^{\circledR}$ e Nestlé ${ }^{\circledast}$ concentraram as maiores frequências de infrações com 31,3\% e 16,6\% respectivamente, ressaltando que aqui no Brasil, a Empresa Nutricia ${ }^{\circledR}$ é a que comercializa os alimentos da marca Danone ${ }^{\circledR}$ (Hadihardjono et al., 2019).

Piwoz e Huffman (2015) apontaram em seu estudo que quatro empresas - Nestlé ${ }^{\circledR}$, Danone ${ }^{\circledR}$, Mead Johnson ${ }^{\circledR}$ e Abbott ${ }^{\circledR}$ - concentraram mais de $50 \%$ de todas as vendas de alimentos para bebês em todo o mundo, sendo que dos US\$ 58 bilhões de vendas em 2013, 69\% das vendas foram de fórmula de leite.

Quanto aos produtos, nos quais foram encontradas infrações, em Belém o produto denominado NAN ${ }^{\circledR}$ da empresa Nestlé ${ }^{\circledR}$, concentrou o maior número de irregularidades com um total de $46 \%$, seguido do produto APTAMIL ${ }^{\circledR}$ da Empresa Danone $^{\circledast}$, com um total de 30\% de descumprimentos. Em São Paulo, o comportamento das infrações foi um pouco diferente, com o produto APTAMIL ${ }^{\circledR}$ da Empresa Danone ${ }^{\circledR}$ ocupando a liderança das transgressões, totalizando 38,5\% dos achados em desacordo com a legislação, seguido do produto NESTOGENO ${ }^{\circledR}$ da Empresa Nestlé ${ }^{\circledR}$, com 25,6\% de desrespeito a Norma.

A maior frequência de infrações, seja pelo número de estabelecimentos, quanto de irregularidades em si, se concentrou em Belém, contudo, é válido ressaltar que tais pesquisas de monitoramento da Norma, ocorreram muito pouco na capital paraense ao longo dos anos (Salve et al., 2008; Salve et al., 2011).

Em contrapartida, em todas as pesquisas de monitoramento da Legislação, São Paulo foi uma das localidades que esteve sendo monitorada no passar dos anos, o que deveria, a priori, garantir que tal localidade estivesse mais alinhada à Legislação vigente (IBFAN, 2008; IBFAN, 2013; IBFAN, 2015; IDEC, 2013; IDEC, 2020; Toma et al., 2005; Toma et al., 2006; Salve et al., 2008; Salve et al., 2011). Ocorre que na prática isto não se confirma, uma vez que mesmo tendo um menor número de infrações quando comparada a Belém, ainda assim o quantitativo encontrado possui números expressivos, e em produtos que desde a instituição da NBCAL, tem sua promoção comercial proibida (Brasil, 1992; Brasil, 2001; Brasil, 2002; Brasil, 2006; Brasil, 2015; Brasil, 2018). 
Nota-se ainda que a Indústria de alimentos voltados à primeira infância vem investindo intensamente em marketing abusivo para promover seus produtos em detrimento da amamentação. Apesar de todos os avanços das Leis brasileiras, a Indústria ainda busca mecanismos para burlar a Legislação vigente e a fiscalização deficitária reforça as investidas das empresas em continuar a promover este marketing abusivo (Monteiro, 2006).

\section{Considerações Finais}

O presente estudo ressalta a importância de maior investimento em prol da proteção à amamentação e aponta para a necessidade de aplicação de fiscalização, ações educativas e punições de acordo com a legislação, a fim de coibir as práticas comerciais que ferem a NBCAL e colocam em perigo a prática do aleitamento materno nas duas localidades, além do reforço dos canais de denúncia dos atos que vão de encontro à Legislação.

Em futuros estudos, sugere-se pesquisar sobre os conhecimentos e as condutas dos gerentes dos estabelecimentos comerciais, além de estudos de intervenção com estratégias educativas sobre a NBCAL, no sentido de garantir sua efetivação e o desempenho do seu papel de proteção à amamentação.

Sugere-se também estudos junto aos grupos gestores da NBCAL nos municípios, como por exemplo os atores da vigilância sanitária, a fim de identificar o conhecimento sobre a Norma, as ações de fiscalização, o percurso e o resultado das denúncias de infração.

\section{Referências}

Amaral, L. J. X., Sales, S. S., Carvalho, D. P. S. R. P., Cruz, G. K. P., Azevedo, I. C., \& Junior, M. A. F. (2015). Fatores que influenciam na interrupção do aleitamento materno exclusivo em nutrizes. Rev Gaúcha Enferm, 36(esp):127-134.

Araújo, M. F. M., Rea, M. F., Pinheiro, K. A., \& Schmitz, B. A. S. (2006). Avanços na norma brasileira de comercialização de alimentos para idade infantil. Rev Saúde Pública, 40(3): 513-520.

Brasil. (1992). Resolução CNS/MS n 31, de 12 de outubro de 1992, D.O de 13/10/1992. Aprovar a Norma Brasileira para Comercialização de Alimentos para Lactentes, a ser observada em todo o território nacional, na forma do Anexo desta Resolução. Diário Oficial da União. Conselho Nacional de Saúde.

Brasil. (2001). Portaria n ${ }^{\circ}$ 2.051, de 08 de novembro de 2001. Estabelece "Os novos critérios da Norma Brasileira de Comercialização de Alimentos para Lactentes e Crianças de Primeira Infância, Bicos, Chupetas e Mamadeiras, a ser observada e cumprida em todo o Território Nacional, constante do ANEXO desta Portaria e que dela é parte integrante". Diário Oficial da União. Ministério da Saúde (MS), Gabinete do Ministro.

Brasil. (2002). Resolução RDC n 222, de 05 de agosto de 2002. Aprova o "Regulamento Técnico para Promoção Comercial de Alimentos para Lactentes e Crianças de Primeira Infância". Diário Oficial da União. Ministério da Saúde (MS). ANVISA - Agência Nacional de Vigilância Sanitária.

Brasil. (2006). Lei n ${ }^{\circ} 11.265$, de 03 de janeiro de 2006. Regulamenta “A comercialização de alimentos para lactentes e crianças de primeira infância e também a de produtos de puericultura correlatos". Diário Oficial da União. Presidência da República.

Brasil. (2015). Decreto n 8.552, de 03 de novembro de 2015. Regulamenta a "Lei no 11.265, de 3 de janeiro de 2006, que dispõe sobre a comercialização de alimentos para lactentes e crianças de primeira infância e de produtos de puericultura correlatos". Diário Oficial da União. Presidência da República.

Brasil. (2018). Decreto n ${ }^{\circ}$ 9.579, de 22 de novembro de 2018. Consolida "Atos normativos editados pelo Poder Executivo federal que dispõem sobre a temática do lactente, da criança e do adolescente e do aprendiz, e sobre o Conselho Nacional dos Direitos da Criança e do Adolescente, o Fundo Nacional para a Criança e o Adolescente e os programas federais da criança e do adolescente, e dá outras providências". Diário Oficial da União. Presidência da República.

Bridge, G., Lomazzi, M., \& Bedi, R. (2020). A cross-country exploratory study to investigate the labelling, energy, carbohydrate and sugar content of formula milk products marketed for infants. British Dental Journal, 228 (3): 198-212.

Cyrillo, D. C., Sarti, F. M., Farina, E. M. Q., \& Mazzon, J. A. (2009). Duas décadas da Norma Brasileira de Comercialização de Alimentos para Lactentes: há motivos para comemorar? Rev. Panam. Salud Pública, 25 (2): 134-140.

Grummer-Strawn, L. M., Zehner, E., Stahlhofer, M., Lutter, C., Clark, D., Sterken, E., Harutyunyan, S., \& Ransom, E. I. (2017). New World Health Organization guidance helps protect breastfeeding as a human right. Matern Child Nutr. 1-3:e12491.

Hadihardjono, D. N., Green, M., Stormer, A., Agustino, Izwardy, D., \& Champeny, M. (2019). Promotions of breastmilk substitutes, commercial complementary foods and commercial snack products commonly fed to young children are frequently found in points- of-sale in Bandung City, Indonesia. Matern Child Nutr., 15(S4): 1-13.

Hernández-Cordero, S., Lozada-Tequeanes, A. L., Shamah-Levy, T., Chessa, L., Cosío, T. G., Saturno-Hernández, P., Dommarco, J. R., \& Grummer-Strawn, L. (2019). Violations of the International Code of Marketing of Breast-milk Substitutes in Mexico. Matern Child Nutr., 15:e12682 1-10. 
IBFAN. (2008). A Promoção de produtos pela internet: Um resumo da IBFAN Brasil 2007/2008. IBFAN Brasil.: http://www.ibfan.org.br/monitoramento/pdf/doc-321.pdf

IBFAN. (2010). Por crianças mais saudáveis. Revista do IDEC [Internet]. 2010;24-7.: http://www.ibfan.org.br/monitoramento/pdf/doc-581.pdf.

IBFAN. (2013). Atração perigosa. Revista do IDEC. IBFAN Brasil.: http://www.ibfan.org.br/site/monitoramento-da-nbcal.

IBFAN. (2015). Amamentação desvalorizada. Revista do IDEC.: https://idec.org.br/em-acao/revista/ao-poupador-as-migalhas/materia/amamentacodesvalorizada.

IDEC. (2013). Conheça a pesquisa de monitoramento de 2013. IDEC.: https://idec.org.br/em-acao/em-foco/conheca-a-pesquisa-de-monitoramento-de-2013.

IDEC. (2020). Monitoramento IDEC - NBCAL dos anos de 2016, 2017, 2018 e 2019. Dados consolidados. Revista do IDEC.: https://idec.org.br/defesa-daamamentacao/monitoramento.

Monteiro, R. (2006). Norma brasileira de comercialização de alimentos para lactentes e crianças de primeira infância: histórico, limitações e perspectivas. Rev. Panam. Salud Pública, 19 (5): 354-362.

Oliveira, C. S., Iocca, F. A., Carrijo, M. L. R., \& Garcia, R. A. T. M. (2015). Amamentação e as intercorrências que contribuem para o desmame precoce. Rev Gaúcha Enferm., 36(esp): 16-23.

Paula, L. O., Chagas, L. R., \& Ramos, C. V. (2010). Monitoramento da norma brasileira de comercialização de alimentos infantis. Rev. Soc. Bra. Ali. Nutr., 35 (3): 43-55.

Piwoz, E. G., \& Huffman, S. L. (2015). The Impact of Marketing of Breast-Milk Substitutes on WHO-Recommended Breastfeeding Practices. Food and Nutrition Bulletin, Vol. 36(4) 373-386.

Pries, A. M., Huffman, S. L., Mengkheang, K., Kroeun, H., Champeny, M., Roberts, M., \& Zehner, E. (2016). Pervasive promotion of breastmilk substitutes in Phnom Penh, Cambodia, and high usage by mothers for infant and young child feeding. Maternal \& Child Nutrition, 12 (Suppl. 2 ): $38-51$.

Rocci, E., \& Fernandes, R. A. Q. (2014). Dificuldades no aleitamento materno e influência no desmame precoce. Rev Bras Enferm, 67(1): 22-27.

Salve, J., Divitiis, R. De, \& Müller, F. S. (2011). Violando as Normas - 2011. Resumo do Relatório de Monitoramento Nacional da NBCAL e Lei 11.265/2006. IBFAN: https://www.mprs.mp.br/media/areas/infancia/arquivos/relatorio_ibfan_nbcal.pdf

Salve, J. M., Divitiis, R. De, \& Toma, T. S. (2008). Relatório nacional das violações à norma brasileira de comercialização de alimentos para lactentes e crianças de primeira infância, bicos, chupetas e mamadeiras e Lei 11.265/2006: edição comemorativa dos 20 anos da NBCAL. Instituto de Saúde/IBFAN Brasil.: http://www.ibfan.org.br/monitoramento/pdf/doc-360.pdf

Silva, K. B., Oliveira, M. I. C., Boccolini, C. S., \& Sally, E. O. F. (2020). Promoção comercial ilegal de produtos que competem com o aleitamento materno. Rev Saúde Pública, 54:1-10.

Silva, N. M., Waterkemper, R., Silva, E. F., Cordova, F. P., \& Bonilha, A. L. L. (2014). Conhecimento de puérperas sobre amamentação exclusiva. Rev Bras Enferm., 67 (2): 290-295.

Toma, T. S., Divitiis, R. De, \& Cotrim, L. C. (2005). Relatório de monitoramento da Norma Brasileira de Comercialização de Alimentos para Lactentes e Crianças de Primeira Infância, Bicos, Chupetas e Mamadeiras: Alcance e resultados 2004. IBFAN: http://www.ibfan.org.br/monitoramento/pdf/moni2004R.pdf

Toma, T. S., Divitiis, R. De, \& Salve, J. (2006). Monitoramento 2006: Um resumo. IBFAN: http://ibfan.org.br/monitoramento/pdf/moni2005.pdf

Zhao, J., Li, M., \& Freeman, B. (2019). A Baby Formula Designed for Chinese Babies: Content Analysis of Milk Formula Advertisements on Chinese Parenting Apps. JMIR Mhealth Uhealth., 7 (11): e14219; 1-12. 